\title{
Time rate of swelling of compacted highly plastic clay soil from Sudan
}

\author{
${ }^{1}$ A M Elsharief, ${ }^{2}$ Mai Sufian \\ ${ }^{1}$ University of Khartoum, Khartoum, Sudan \\ ${ }^{2}$ Sudan University of Science and Technology, Khartoum, Sudan
}

\begin{abstract}
This paper investigates the development of swelling with time for a highly plastic and potentially expansive clay from Sudan. Soil samples were prepared in the laboratory at different moisture content values. The prepared samples were placed in the oedometer ring at three density levels and then placed in an oedometer cell which allows one dimensional swelling. Swelling was observed at different time intervals to 48 hours. The data was analyzed to determine the development of swelling with time. The data analysis clearly demonstrated three stages of swelling, initial, preliminary and secondary for all tested samples except the quasi-saturated ones. The swell percent and primary swelling were very sensitive to the initial moisture content and dry density of the tested samples. Most of the swelling took place during the first 24 hours for all the tested specimens. The hyperbolic model was assessed for prediction of the percent swell. The 12 hours data was found to be very successful in predicting the percentage swell.
\end{abstract}

\section{Introduction}

Swelling takes place when water percolatesinto the pores of a potentially expansive soil. The potential for a compacted soil to swell is governed by its intrinsic and extrinsic properties. The important intrinsic properties are the soil composition and the mineralogical characteristics of the clay fraction whereas the extrinsic properties are the placement water content, densityand loading [1]. Moisture migration depends on the existence of water source and a potential gradient to drive water into the soil. The percolation potential constitutes three components: gravitational potential, overburden potential and matric suction potential [2]. The first two are negligible compared to the matric suction potential which is responsible for driving water into clay soils [2]. Matric suction of a certain clay is governed by its water content and pore size characteristics which are partly controlled by its density.

Swelling is a time dependent process. It takes place over relatively long time in three distinct stages: initial, primary and secondary [3].The intrinsic and placement factors affect the magnitude and duration of these swelling stages [4]. This paper looks into the different stages of swellingof a highly plastic compacted swelling soil from Sudan.

\section{Time rate of swelling for compacted clay soils}

The factors controlling the time rate of swelling of compacted clays are: soil composition, density, water content, matric suction and fabric. Dry of optimum compacted clays have flocculated structurewhereas wet of optimum clays have dispersed structure [5].The time rate of swelling varies with the swelling stages, i.e., initial, primary and secondary stages.

The swelling behavior of compacted sandbentonite mixtures follows a standard ' $S$ ' shape[3]. Figure 1 shows typical swell curve for a compacted fine-grained soil plotted on a semi-logarithmic scale. Swelling occurs in three stages: initial or inter-void swelling which comprises $10 \%$ of total swelling; primary swelling comprising $80 \%$ of total swelling and secondary swelling beyond $90 \%$ total swell[3]. Initial swelling is due to hydration of the surface of clay particlessuch 
thatswelling takes place within the voids of the non-swelling fraction; primary swelling is due to double layer effectsand develops at faster rate when the voids can no longer accommodate further clay particle swelling whereas secondary swelling is explained by the flow processes associated with bimodal pore size distribution for the swelling soil [6]. Secondary swelling is slow compared to the initial and primary swelling stages.

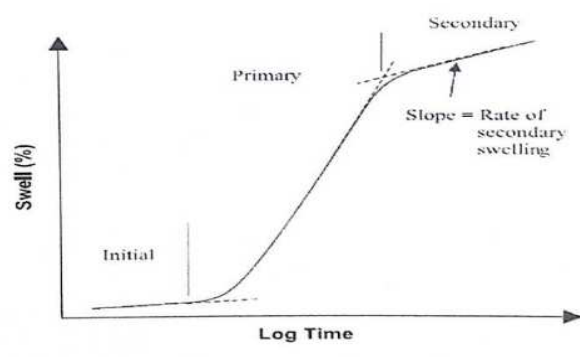

Fig. 1.Schematic of swell versus log of time

When assessing the rate of swelling, the swelling data is often plotted as percentage swell versus time. Time is either plotted on normal scale or on $\log _{10}$ scale. Dakshanamurthy[7] proposed a hyperbolic equation to predict swelling of expansive soils as given below

$\varepsilon=\frac{t}{(a+b t)}$

Where:

$\varepsilon=$ percentage swell

$\mathrm{t}=$ time

$\mathrm{a}$ and $\mathrm{b}$ are constants

$\mathrm{a}$ and $\mathrm{b}$ can be determined by linearizing the non-linear curve through plotting $t / \varepsilon$ versus $t$.

$t / \varepsilon=a+b t(2)$

Here $b$ is the slope of the swelling path and is defined as the coefficient of the rate of swelling [8]. The maximum swell percent can be predicted from equation (1) as follows:

$\varepsilon \max =\lim _{t \rightarrow \infty}\left(\frac{1}{\frac{a}{t}+b}\right)=1 / b$

Theoretically the maximum swell percent is the inverse of the coefficient of the rate of swelling. Several researchers have predicted the maximum swell using the hyperbolic model [8].

When $\varepsilon$ is plotted versus $\log _{10}(\mathrm{t})$ linear relationships are realized for the different stages of swelling. The time rate of swelling for each stage is given by
Cs $=7 \varepsilon / 2 \log _{10} t(4)$

Where $\varepsilon$ and $\mathrm{t}$ cover the swelling stage under consideration

\section{Soil material and test methods}

The soil used in this study is a highly plastic silty clay soil obtained from Alfao in eastern Sudan. The basic soil's physical and engineering properties are as follows: liquid limit is 70 , plasticity index is 40 , clay fraction $48 \%$,maximum dry density is $1.43 \mathrm{~g} / \mathrm{cm}^{\wedge} 3$ and o.m.cis 29.5. The soil is classified, according to the Unified Soil Classification System as highly plastic silty clay $(\mathrm{CH})$.

The objective of the testing program was to study the swelling stages of a compacted clay sample prepared at different water contents and dry densities. The dry densities applied in this research were $1.25 \mathrm{~g} / \mathrm{cm}^{3}, 1.35 \mathrm{~g} / \mathrm{cm}^{3}$ and 1.45 $\mathrm{g} / \mathrm{cm}^{3}\left(+-0.1 \mathrm{~g} / \mathrm{cm}^{3}\right)$. For each of the three density levels, the soil specimens were prepared at five different water contents; two specimens dry of optimum, one at optimum and two wet of optimum water content. The soil samples were airdried, crushed and pulverized and water was added to attain the target water content.

The tested specimen was manually compacted carefully inside the oedometer ring at the required water content to the target dry density and then mounted into the oedometer cell which allows one-dimensional swelling. To eliminate the effects of loading on the sample and allow free sample swell, very light plastic cover was placed on the sample and distilled water was then added. Swelling was measured at specified intervals for 48 hours.

\section{Data analysis}

The swell percent is plotted versus time for dry density $1.25 \mathrm{~g} / \mathrm{cm}^{3}$ (Figure 2) and swell percent versus $\log _{10}$ t,Figures 3 , Figure 4 and Figure 5 for dry densities $1.25 \mathrm{~g} / \mathrm{cm}^{3}, 1.35 \mathrm{~g} / \mathrm{cm}^{3}$ and $1.45 \mathrm{~g} / \mathrm{cm}^{3}$, respectively. The swelling stages are more evident when we look at the swell versus time relationship. Figure 2 clearly shows three trends in the flow of the curve; initial fast increase in percentage swell with time and then gradual increase shown by the formation of a curve and finally very small increase of swell with time explained by the asymptotic line.The analysis of data confirms the evolution of the three stages of swelling: initial, primary and secondary. It took less than five minutes for the initial stage of swelling to take place whereas the primary stage continued to 6 to 12 
hours (360 to 720 minutes) and the secondary swelling resumes after 12 hours.

Thetime rate of initial swell(Cs in equation 4) is faster for the drier and denser samples and decreases with increase in the molding water content. The first minute witnessed large volume change especially which amounts to more than $25 \%$ for the drier and denser sample (Figure 5). The time rate of initial swell decreases with decrease in density and with increase in water content. However, it is evident from the data thatmolding water content has more impact on the amount and rate of swelling when compared to dry density.This is more evidentwhen comparing dry of optimum tests results with the wet of optimum ones. The bottom curves (wet of optimum samples), Figures 3, 4 and 5, are almost identical for the initial stage of swelling and separate from each other during the following stages.The rate of primary swelling,for all densities and water contents, ranges from about 0.02 to about 0.045 whereas the rate of secondary swelling ranges between 0.02 to 0.002 , both of them decrease with increasein water content.

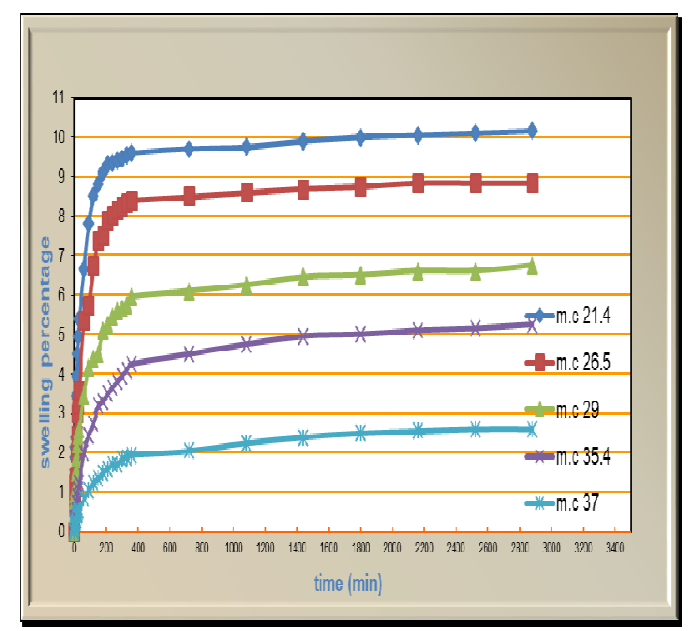

Fig. 2. Swell percent versus time for different water contents (dry density $1.25 \mathrm{~g} / \mathrm{cm}^{3}$ )

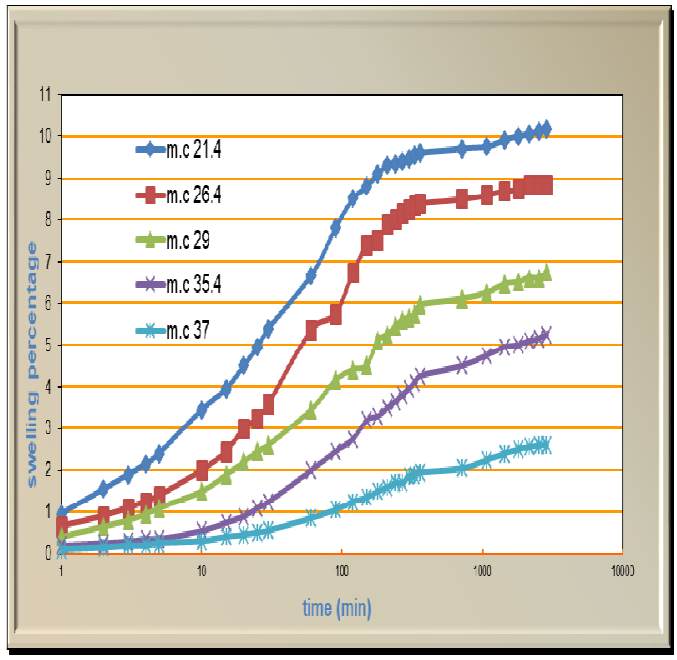

Fig. 3. Swell percent versus log time for different water contents (dry density $1.25 \mathrm{~g} / \mathrm{cm}^{3}$ )

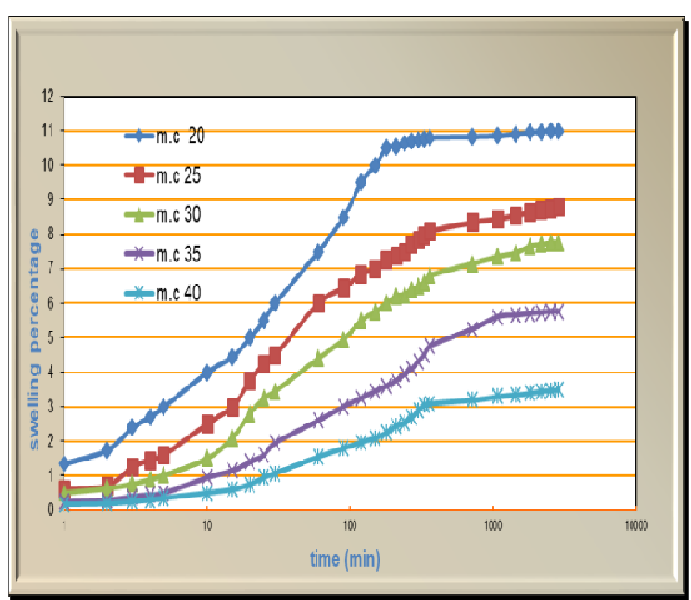

Fig. 4. Swell percent versus log time for different water contents (dry density $1.35 \mathrm{~g} / \mathrm{cm}^{3}$ )

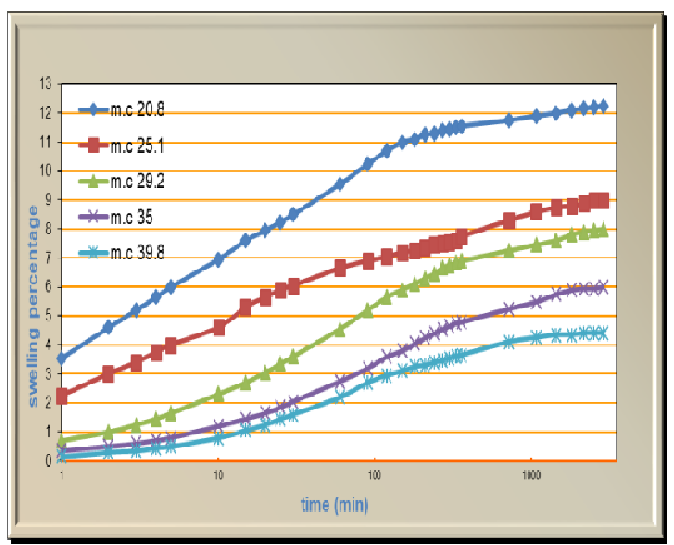

Fig. 5. Swell percent versus log time for different water contents (dry density $1.45 \mathrm{~g} / \mathrm{cm}^{3}$ )

The hyperbolic model was used to predict the percentage swell for the test data. From equation $(2), t / \varepsilon * t_{0}$ is plotted,for the whole data, against $\mathrm{t} / \mathrm{t}_{\mathrm{o}}$ for dry density $12.5 \mathrm{~g} / \mathrm{cm}^{3}$ and all water content values (Figures 6); here $t_{o}$ is taken as 100. The plots show straight line 
relationship and very good correlation especially for the primary and secondary swelling stages. The coefficient of correlation is greater than 0.99 for all the tested specimens, i.e. for all water content values. The slope of the straightlineincreases with increase in water content values. The values of $a$ and $b$ in equation (2)were determined. The theoretical maximum percent swell $(1 / b)$ was determined for all the tests data and compared with the measured percent swell after 48 hours test time (Figure 7). The slope of the straight line joining the points is about unity, therefore the 48hour percent swell is good approximation of the theoretical maximum percentage swell.

The percent swell was plotted against timefor different time periods, i.e. 180 and 720 for dry density equals $12.5 \mathrm{gcm}^{3}$ (Figure 8 and Figure 9). The correlation coefficient was determined for each time period. Excellent correlation $\left(\mathrm{R}^{2}>=0.99\right)$ is assured for 720 minutes testingtime. Therefore, the hyperbolic model can be utilized for predicting the maximum percent swell if test data is available for twelve hours. The plots also show that the initial swell data do not fit well to the hyperbolic model, therefore the model best applies to the primary and secondary swell data.

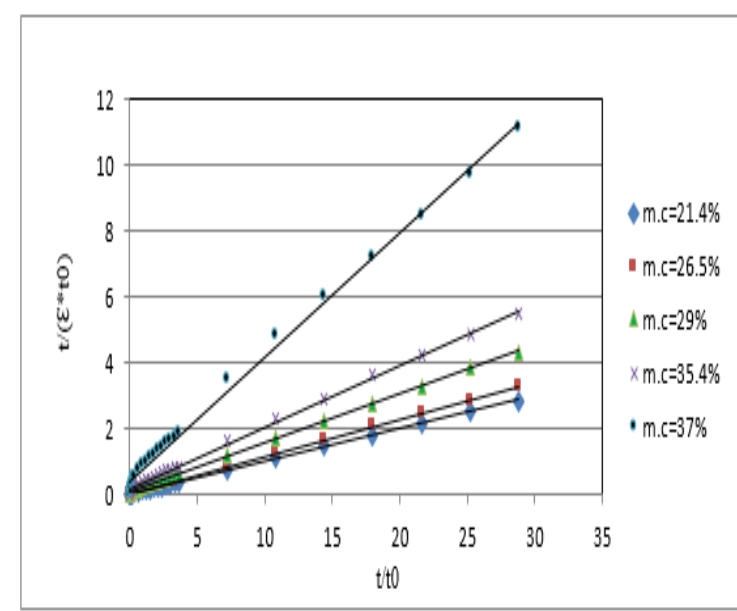

Fig. 6. $t / \varepsilon$ versus time for the test data (dry density $1.25 \mathrm{~g} / \mathrm{cm}^{3}$ )

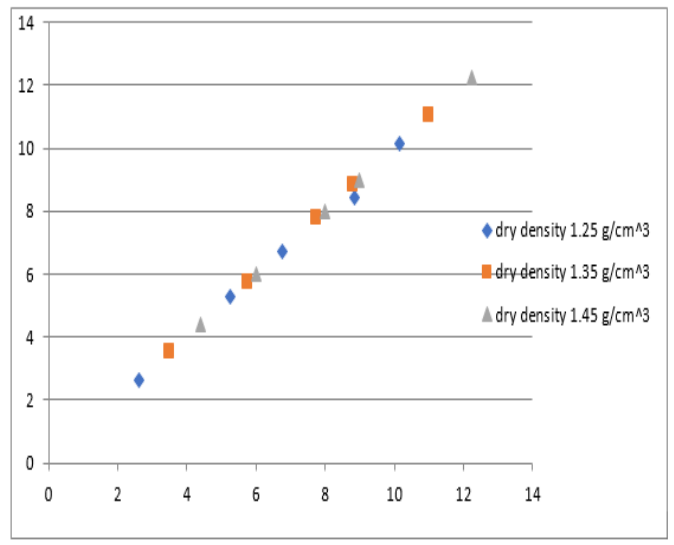

Fig. 7. Computed versus measured percent swell values for all the test data

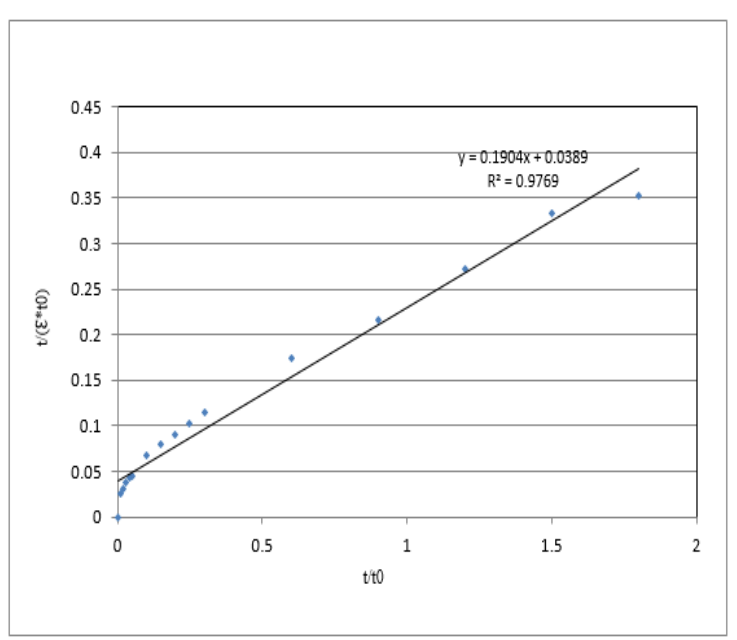

Fig.8. $t / \varepsilon$ versus time for the up to 180 minutes of testing (dry density $1.25 \mathrm{~g} / \mathrm{cm}^{3}$ )

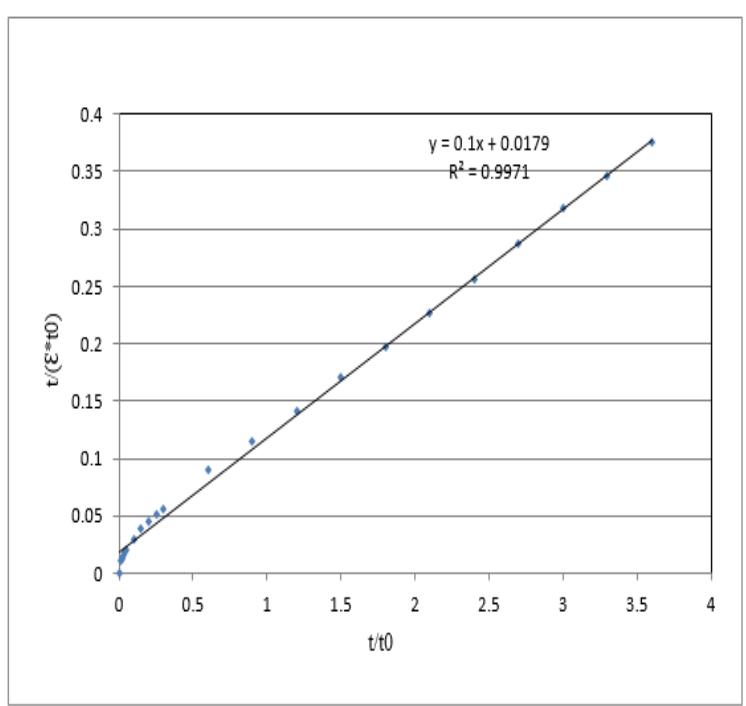

Fig. $9 t / \varepsilon$ versus time for the test data for up to 720 minutes of testing (dry density $1.25 \mathrm{~g} / \mathrm{cm}^{3}$ ) 


\section{Conclusions}

This paper presented the analysis ofdata of extensive free swell tests performed on a highly plastic silty clay from Alfao in eastern Sudan. The clay is known for its very high potential for swelling. The objective was to study the development of swelling with time, the different swelling stages, amounts and times and determine the swell percent for samples compactedat various densities and water contents. The test specimens were prepared in the oedometer ring at three density levels and dry of optimum, about optimum and wet of optimum water contents.

The swell percent versus time and swell versus log time plots clearly demonstrate three stages of swelling namelyinitial, preliminary and secondary swell. The initial swell took place in less than 5 minutes for all density and moisture content conditions except for the very highwater contents. The secondary swell continues for about 720 minutes whereas the secondary swell dominates after that.

The rate of primary swell decreases as water content increases and is in the range 0.02 to 0.045 . The rate of secondary swell is lower than the rate of primary swell and ranges from 0.002 to 0.02 , both of them decrease with increase in water content

The hyperbolic model could be used to predict the maximum swell. The 48 hours swell data accurately predicted the maximum swell. The data analysis has shown that the 720 minutes could be used to predict the maximum swell with excellent accuracy for dry of optimum specimens and very good accuracy for wet of optimum specimens.

\section{References}

[1] J. D. Nelson and D. J. Miller,Expansive Soils, Problems and Practice in Foundation and Pavement Engineering, John Wiley \& Sons Inc., New York, (1992)

[2] Sokolov and J. M. Amir, Moisture Distribution in Covered Clays, $3^{\text {rd }}$ International Conference on Expansive Soils, Haifa pp. 129-136 (1973)

[3] P. V. Sivapullaiah, A. Sridharan, and V. K. Stalin, Swelling Behavior of Soil-Bentonite Mixtures, Canadian Geotechnical Journal, Vol.33/5, 808-814 (1996).

[4] A. Sridharan and Y. Gurtug, Swelling Behavior of Compacted Fine-Grained Soils, Engineering Geology 72 9-18, (2004)

[5] J. K. Mitchell, Fundamentals of Soil Behavior, Wiley, London, p.422 (1976)

[6] J. T. Das, Evaluation of the Rate of Secondary Swelling in Expansive Clay Soils Using Centrifuge Technology, M.Sc. thesis, University of Texas, Austin,(2014)

[7] V. Dakshanamurthy, A new Method to Predict Swelling Using Hyperbolic Equation, Geotechnical Engineering,Vol. 9, pp. 79-87 (1978)

[8] R. Hashim and A. S. Muntohar, Swelling Rate of Expansive Clay Soils, Recent Advances in Characterization and Treatment, edited by A. A. Al-Rawas and F. A. Goosen, Taylor and Francis Group pp. 139-148 (2006) 